\title{
AIDS-Related Kaposi Sarcoma T0 (Good Risk): Localized Tumor
}

National Cancer Institute

\section{Source}

National Cancer Institute. AIDS-Related Kaposi Sarcoma TO (Good Risk): Localized

Tumor. NCI Thesaurus. Code C134971.

AIDS-related Kaposi sarcoma is only in the skin and/or the lymph nodes, and/or there is only a small amount of disease on the palate. The Kaposi sarcoma lesions in the mouth are flat rather than raised. (American Cancer Society) 